\title{
Habitat continuity and stepping-stone oceanographic distances explain population genetic connectivity of the brown alga Cystoseira amentacea
}

\author{
ROBERTO BUONOMO, ${ }^{*}$ (iD JORGE ASSIS, * FRANCISCO FERNANDES,* \\ ASCHWIN H. ENGELEN, * LAURA AIROLDI† and ESTER A. SERRÃO* \\ *CCMAR-CIMAR Laboratorio Associado, F.C.T.- Universidade do Algarve, Campus de Gambelas, 8005-139, Faro, Portugal, \\ $\uparrow$ Dipartimento di Scienze Biologiche, Geologiche ed Ambientali, UO Conisma, University of Bologna, Via S. Alberto 163, 48123, \\ Ravenna, Italy
}

\begin{abstract}
Effective predictive and management approaches for species occurring in a metapopulation structure require good understanding of interpopulation connectivity. In this study, we ask whether population genetic structure of marine species with fragmented distributions can be predicted by stepping-stone oceanographic transport and habitat continuity, using as model an ecosystem-structuring brown alga, Cystoseira amentacea var. stricta. To answer this question, we analysed the genetic structure and estimated the connectivity of populations along discontinuous rocky habitat patches in southern Italy, using microsatellite markers at multiple scales. In addition, we modelled the effect of rocky habitat continuity and ocean circulation on gene flow by simulating Lagrangian particle dispersal based on ocean surface currents allowing multigenerational stepping-stone dynamics. Populations were highly differentiated, at scales from few metres up to thousands of kilometres. The best possible model fit to explain the genetic results combined current direction, rocky habitat extension and distance along the coast among rocky sites. We conclude that a combination of variable suitable habitat and oceanographic transport is a useful predictor of genetic structure. This relationship provides insight into the mechanisms of dispersal and the role of life-history traits. Our results highlight the importance of spatially explicit modelling of steppingstone dynamics and oceanographic directional transport coupled with habitat suitability, to better describe and predict marine population structure and differentiation. This study also suggests the appropriate spatial scales for the conservation, restoration and management of species that are increasingly affected by habitat modifications.
\end{abstract}

Keywords: conservation biology, habitat degradation, landscape genetics, population genetics empirical

Received 12 March 2016; revision received 11 November 2016; accepted 14 November 2016

\section{Introduction}

The application of landscape genetics in the marine environment, known as 'seascape genetics', focuses mainly on the comparison of expected dispersal with observed

Correspondence: Roberto Buonomo, Fax: +39 0544937 303;

E-mail: buonomo.roberto@gmail.com, Laura Airoldi;

E-mail: laura.airoldi@unibo.it and Ester A. Serrão;

E-mail: eserrao@ualg.pt pairwise genetic differentiation (Johansson et al. 2008; White et al. 2010; Coscia et al. 2012), detection of dispersal barriers to gene flow (Schultz \& Feldheim 2008; Collins et al. 2010; Neiva et al. 2012) and testing specific ecological hypotheses (Collins et al. 2010; Crandall et al. 2012). As high-resolution data on ocean currents become available (Siegel \& Kinlan 2003), connectivity and dispersal can be better described with improved oceanographic models simulating particle movement. However, in seascape genetics, oceanographic data are often used only 
qualitatively to explain population genetic structure. Explicit tests of effects of dispersal probabilities derived from oceanographic models on estimated genetic data have been applied in the last decade (Galindo et al. 2006). This quantitative approach offers a framework to analyse the relevance and influence of different environmental features on gene flow and genetic structure (Storfer et al. 2007; Alberto et al. 2010, 2011; Sunday et al. 2014). Genetic differentiation and probability of migration from oceanographic models can also be combined with fine-scale seascape features, such as canopy or temperature, to explain genetic structure for multiple species (Selkoe et al. 2010). The relative influence of seascape variables can be tested (e.g. Storfer et al. 2007; Alberto et al. 2010, 2011), to compare alternative ecological hypotheses on factors affecting the genetic structure of marine populations.

This study addresses two challenges in seascape genetics research, asymmetrical dispersal and multigeneration dispersal effects linking sites by steppingstone movements. Although the most commonly tested seascape feature is Euclidian distance, predicted to be inversely related to gene flow (Rousset 1997), isolationby-distance models can be insufficient if seascape features are unequally distributed between populations. For example, ocean currents are often predominantly unidirectional; therefore, even close populations might be differentially isolated by ocean circulation (Collins et al. 2010). Asymmetrical dispersal can result in a source-sink population structure where the demographic context of each population influences its evolutionary potential (Kawecki \& Holt 2002), but it is often an overlooked factor. Furthermore, population connectivity is increasingly affected by a variety of human modifications to the environment (Jones 2007), leading to habitat fragmentation and loss and genetic disjunction even at small spatial scales (Fraser et al. 2010; Alberto et al. 2011) or alternatively introducing novel artificial urban habitats that can act as a conduit for some species across the seascape (Airoldi et al. 2015). Any of these effects would be particularly relevant for species with low dispersal ability, affecting their capability to recover from disturbances, colonize new habitats or migrate, as response to future climate changes (Opdam \& Wascher 2004; Thrush et al. 2013). The potential for local adaptation to environmental variations may also be modified by changing genetic variability and connectivity (Kawecki \& Ebert 2004; Chevin et al. 2010). Potential limitations to dispersal in a marine metapopulation system can be caused by the species' dispersal biology, oceanographic transport and the spatial distribution of suitable habitat. These can in turn affect population genetic diversity and connectivity. The effects of these processes should be considered in coastal management and restoration (McKay et al. 2005). This goal can be achieved by modelling the stepping-stone dynamics of species among fragmented patches of suitable habitats.

Marine dispersal has rarely been evaluated in a stepping-stone mode, and the few cases that did so have generally focused on species with long pelagic larvae duration (Treml E et al. 2007; Crandall et al. 2012). Here, we focused on species with low dispersal capacity, expected to be highly differentiated and which might depend strongly on stepping-stone dispersal to achieve genetic connectivity. This is expected to be the case of fucoid algae belonging to the genus Cystoseira, whose zygotes develop attached to the maternal alga and sink directly underneath, having no planktonic life stages. These are among the most relevant ecosystem engineering species in the Mediterranean Sea and used to form extensive canopy 'forests' on suitable rocky substrate (Airoldi \& Beck 2007). Nowadays, these biogenic habitats are threatened by increasing urbanization and habitat loss (Benedetti-Cecchi et al. 2001; Mangialajo et al. 2008), sometimes to local extinction (Perkol-Finkel \& Airoldi 2010; Airoldi et al. 2014; Thibaut et al. 2015). Recent work has tried to understand what factors can facilitate the persistence of populations of Cystoseira spp. across a range of increasing anthropogenic and climatic stressors and habitat modifications (Strain et al. 2015), and what are the opportunities for restoration in natural and artificial habitats along increasingly urbanized coastlines (Perkol-Finkel et al. 2012; Gianni et al. 2013; Ferrario et al. 2016). These programmes should also incorporate knowledge of genetic structuring and connectivity to ensure that rehabilitation has the best possible chance of success by considering natural scales of dispersal and gene flow.

In this study, we ask whether the genetic structure and genetic connectivity of populations of marine species that can only disperse by rafting can be better predicted by taking into account stepping-stone migration between suitable habitat patches (i.e. rocky habitat continuity) and dispersal pathways inferred from oceanographic currents rather than distance alone. We use as model oceanographic region a complex coastline in southern Italy where geographical and oceanographic distances are uncoupled, therefore providing the opportunity to compare their effects. Our model species is Cystoseira amentacea var. stricta Montagne, chosen to represent low-dispersal species whose propagules do not have a planktonic stage. This trait is expected to result in genetically isolated populations where suitable habitat is discontinuous, only counteracted by transport of reproductive drifting thalli in floating rafts. If connectivity is limited, the consequent smaller population gene 
pools and sizes render populations more vulnerable to threats that cause demographic instability (e.g. recruitment failure due to high sedimentation, Benedetti-Cecchi et al. 2001; Soltan et al. 2001; Ballesteros et al. 2007). We compared genetic and oceanographic estimates of connectivity at different scales to assess the hypothesis that stepping-stone transport by directional currents and habitat continuity could explain the main patterns of genetic differentiation. We chose as model region a complex oceanographic system where simple geographical distance can be distinguished from current transport and rocky habitat continuity.

\section{Cystoseira amentacea life history}

Cystoseira amentacea is an endemic Mediterranean species, restricted to the upper sublittoral zone and highly sensitive to environmental degradation, such as that occurring in proximity of sewage outfalls, ports and urban areas (Benedetti-Cecchi et al. 2001; Soltan et al. 2001; Mangialajo et al. 2008; Falace et al. 2010; Thibaut et al. 2014). It is used as an indicator of good environmental status within the EU Water Framework Directive (2000/60/EC) (Ballesteros et al. 2007). The species has experienced local declines (Zavodnik et al. 2002; Mangialajo et al. 2008; Iveša et al. 2016), although in other regions it has been historically stable (Thibaut et al. 2016), and it is currently protected under the Bern Convention and Barcelona Convention. Little is known about the genetic diversity of this species or any other Cystoseira species (but see Susini et al. 2007a; Robvieux et al. 2012; Robvieux 2013), limiting our understanding of populations and species resilience to local and global stressors.

Dispersal of C. amentacea is very restricted except for transport in floating rafts. Thalli are negatively buoyant, and propagules normally settle at $<20-40 \mathrm{~cm}$ from the source (Mangialajo et al. 2012), strongly limiting the potential dispersal distance. Fragments of thalli can however also be transported entangled in floating rafts of other algae (Susini et al. 2007a), a relatively frequent and documented mechanism of marine dispersal (Thiel \& Gutow 2005). Like most species in the genera Cystoseira and Sargassum, C. amentacea undergoes an annual thallus loss at the end of summer, where the entire frond breaks at the base. The holdfasts overwinter and regrow in the next year. Therefore, although individuals are perennial, the thalli are annual, forming large thallus loss events. To what extent these annual events release fragments that carry viable reproductive structures has not been studied in C. amentacea. However, massive drifting events of reproductive thalli are suggested to be a key factor in the invasion success of Sargassum muticum (e.g. Norton 1976).

\section{Methods}

\section{Study area and sampling design}

Samples were collected along the southern Italian coast at eight different locations (Fig. 1) encompassing the regions of Puglia, Calabria and the island of Sicily, to represent a complex coastline system regarding rocky shore continuity and current patterns. Shallow rocky habitats are naturally fragmented (Fig. 1), particularly due to separation of the mainland and the island of Sicily and because this area comprise the two regions (Sicily and Calabria) with the highest national extension of sandy coastlines (ISPRA 2015). Up to 75\% of the local human populations live within $5 \mathrm{~km}$ from the coast, determining a variety of coastal pressures and transformations (Thompson et al. 2002) further modifying the suitable habitat available for species of Cystoseira (Perkol-Finkel \& Airoldi 2010; Thibaut et al. 2014). In this region, the species presence is historically scattered (Fig. S1, supporting information) and limited by fragmentation of suitable substratum.

The eight locations sampled comprise three populations from the Italian mainland, and two and three populations from the southern and northern coast of Sicily, respectively. Population distances along the coast covered different scales, from hundreds of metres, the distance between three subpopulations at one location, Capo Gallo (Fig. 1), up to about $1000 \mathrm{~km}$ between the most distant population pair. The species was confidently identified in the field as it could be distinguished from other closely related taxa thanks to the expertise of the collectors and according to a local identification guide (Mannino \& Mancuso 2009; identifications were later confirmed by the genetic results). Apical tissue, free from epiphytes, was collected from 30 to 35 individuals haphazardly selected and separated by at least $30 \mathrm{~cm}$ at each study site. Samples were preserved dry in silica gel.

At Capo Gallo, an additional fine-scale sampling scheme was applied along $230 \mathrm{~m}$ of coast. Three $10-\mathrm{m}$ transects were sampled, located $100 \mathrm{~m}$ apart from each other, each consisting of 30 individuals collected every $30 \mathrm{~cm}$. Coordinates were recorded for every individual to allow to estimate exact distances between pairs of individuals. Additionally, five individuals were collected every $25 \mathrm{~m}$ between the three transects, totalling 120 sampled specimens in Capo Gallo. We replicated the spatial autocorrelation analysis in Sant'Elia, but only up to a maximum distance of $34 \mathrm{~m}$. It was not possible to replicate the entire sampling scheme as in Capo Gallo because due to the high degree of local population fragmentation, no other site was found to hold a continuous population along $230 \mathrm{~m}$ of coastline. 


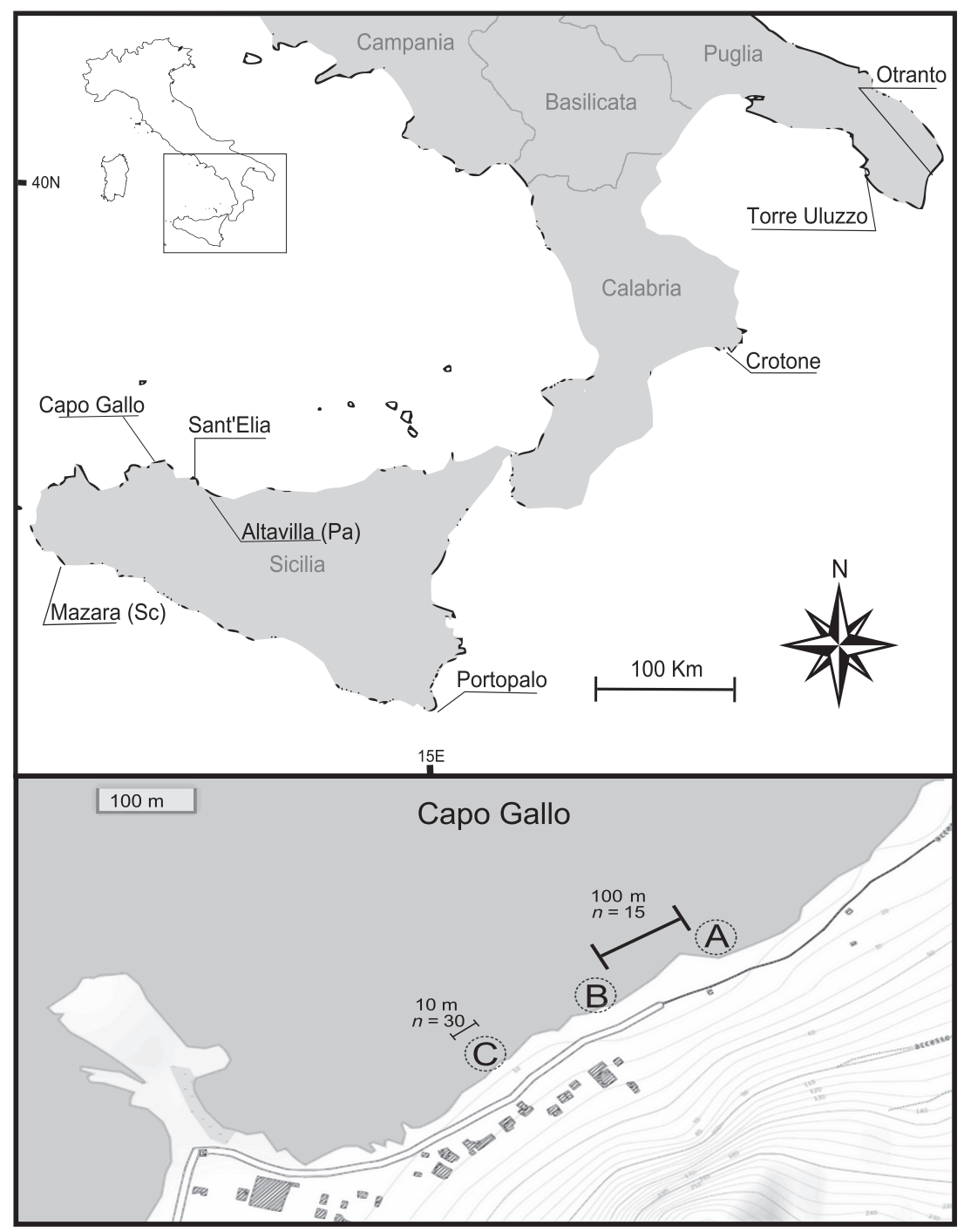

Fig. 1 Map of the study area with the location of the eight sampled Cystoseira amentacea populations. Darker coastline represents areas with rocky shore. Transects A, B and C within Capo Gallo are also shown with respective distances and samples sizes.

\section{Genetic analyses}

Genomic DNA was extracted from algal tissue using a cetyltrimethylammonium bromide (CTAB) method optimized for brown algae (Hoarau et al. 2007). Ten microsatellites previously developed for Cystoseira tamariscifolia (Engelen et al. 2016) were tested, eight of which successfully cross-amplified in Cystoseira amentacea after optimization. These were chosen instead of previously published microsatellites (Robvieux et al. 2012) for future data comparability between these two closely related species. The primer $\mathrm{Ct} 2.3$, excluded for C. tamariscifolia, was included in our analysis because it showed polymorphism across populations (F: GTCGGATGCTCCTCCAGTC, R: AGTGATCTAGCCCA GCGAAG; $(A C)_{10)}$. Fragment lengths were estimated on an ABI PRISM 3130 DNA analyser (Applied Biosystems) with the LIZ 500 (GeneScan) standard. Alleles were scored using the free software STRAND (Toonen \& Hughes 2001) and further binned into size classes with the msatAllele R package (Alberto 2013).

The genotypes obtained per population were used to estimate population diversity (gene diversity and allelic richness) and to test for departures from the null hypothesis of Hardy-Weinberg equilibrium $\left(\mathrm{H}_{0}: \mathrm{F}_{\mathrm{IS}}=0\right)$ using permutations as implemented in GENETIX (Belkhir et al. 1996-2004). Presence of null alleles was estimated with Microchecker (Van Oosterhout et al. 2004), and corrected $F_{\mathrm{ST}}(\theta$, Weir \& Cockerham 1984) accounting for null alleles was estimated with FreeNA (Chapuis \& Estoup 2007). Results of corrected $F_{\mathrm{ST}}$ were compared with the original matrix of genetic distances between 
population pairs. Partition of variance was estimated with AMOVA (Excoffier et al. 1992) in GenALEx (Peakall \& Smouse 2006). The null hypothesis of no pairwise differentiation $\left(F_{\mathrm{ST}}=0\right)$ was tested using 999 permutations of individuals across populations. Optimal population clustering and graphical visualization of population distance were obtained through the Discriminant Analysis of Principal Components (DAPC) approach implemented in the adegenet $\mathrm{R}$ package (Jombart 2008). DAPC minimized the within-individuals genetic variance in the choice of discriminant functions to improve the between-groups genetic variance description (Jombart et al. 2010).

Fine-scale genetic differentiation was tested as variation of the probability of identity by descent between pairs of individuals over the total distance. We calculated the kinship autocorrelation coefficient as the $r$ index (Smouse \& Peakall 1999), a multiallelic codominant loci analysis closely related to Moran's-I index, and plotted the correlogram in GENALEX (Peakall \& Smouse 2006). Statistical significance and confidence intervals were estimated by 999 random permutations.

\section{Habitat continuity and particle dispersal}

To infer the potential connectivity among C. amentacea populations, we developed individual-based Lagrangian numerical simulations (hereafter LNS) following the framework implemented by Assis et al. (2015) and Klein et al. (2016). This modelling approach mimics the species' capacity to disperse between favourable habitat patches via rafting of floating macroalgae (Susini et al. 2007a). The simulation tracked the geographical position of virtual particles advected by surface velocity fields ( $0 \mathrm{~m}$ depth layer) derived from the Hybrid Coordinate Ocean Model (HYCOM), a high-resolution product produced on a daily basis, forced by heat flux, precipitation, wind speed and wind stress (Chassignet et al. 2007). This oceanic model is already validated in the Mediterranean (Xu et al. 2007) and resolves oceanic fronts, filaments, meandering currents and eddies, essential processes to simulate the dispersion of floating rafts (Chassignet et al. 2007; Lett et al. 2008; Young et al. 2012).

Suitable near-shore rocky habitats in southern Italy were digitized (Quantum GIS Development Team 2014) and gridded to $0.01^{\circ} \times 0.01^{\circ}$ cells $(\sim 0.9 \mathrm{~km})$, which is the spatial resolution of the simulation. Individual particles simulated floating rafts of $C$. amentacea by incorporating a set of state variables such as age (day), location (longitude and latitude) and status (drifting or settled). These were released from every cell with favourable habitat on a daily basis and allowed to drift for 30 days throughout summer (Jul-Sep; simulation period per year), the season when the individuals of $\mathrm{C}$. amentacea are reproductive and may associate with other macroalgae, facilitating the drifting of the rafts, which otherwise would be limited due to the negative buoyance of the thalli.

The duration of rafts was established at 30 days according to viability tests on Sargassum spp, one of the plausible vector for the species (Thiel \& Gutow 2005). The longevity of viable reproductive material in rafts is unknown, so the best estimate is provided by laboratory studies in other fucoids that have kept unattached reproductive material releasing gametes for 24 days (Monteiro et al. 2016). As unattached fucoid algae do not produce new reproductive structures (e.g. Norton \& Mathieson 1983), the role of rafts on dispersal must be mediated by the longevity of the reproductive structures produced before detachment. The position of each particle (in geographical coordinates) was calculated every two hours (12 time steps per day) using bilinear interpolation of the daily velocity fields. A fourth-order Runge-Kutta calculation scheme (sampling at midpoints along the distance) was integrated to determine the trajectory of particles throughout the simulated time steps (e.g. Lett et al. 2008).

Dispersal simulations were performed independently per year for an 11-year period (2002-2012). The individual trajectories were used to infer paired probability estimates by determining the steps in the path of each individual particle released from a given cell $i$, that achieved or crossed cell $j$, divided by the number of simulated steps (30 days PD * 12 time steps a day). Squared connectivity matrices between all pairs of sites were produced by averaging the probability outcomes from all particle release events performed in the simulation period of a given year (i.e. 92 particles per cell). Probabilities between samples in Capo Gallo were estimated as the retention probability inside the same cell, as the grid resolution of the oceanographic currents was not small enough to resolve connectivity at that scale. An averaged connectivity matrix between every pair of cells was determined for the 11-year period.

We implemented a graph-theoretical framework to account for the hypothesis of genotypes migrating between suitable habitats' patches on a year-to-year stepping-stone scenario. The Floyd-Warshall's algorithm (Floyd 1962) was used to find the shortest directed path between cells (i.e. the graph nodes), using the paired probabilities from the averaged connectivity matrix as the direct weight between edges (i.e. the graph links). The stepping-stone probabilities were determined by multiplying the probabilities found in the shortest path between all pairs of cells. The averaged and stepping-stone connectivity matrices were used to extract the connectivity estimates between the sites sampled for genetics. LNS were developed in $\mathrm{R}(\mathrm{R}$ 
Core Team 2014) with packages: calibrate, e1071, parallel and raster.

\section{Directionality of oceanographic transport}

An index of directionality was designed to be proportional to the directionality of currents driving particles between sites, being 0 where completely bidirectional and 1 when exclusively unidirectional and calculated as $I_{(i, j)}=\frac{\left(P_{\min }-P_{\max }\right)}{P_{\min }}$, where $P_{\min }$ is the natural logarithm of the minimum probability between sites $i$ and $j$ from the LNS model and $P_{\max }$ the logarithm of the maximum probability between the same sites. The index was developed to test the hypothesis that sites connected with bidirectional gene exchange show lower genetic differentiation compared to sites with unidirectional gene flow.

\section{Modelling}

Linear regressions were used to explain pairwise genetic distances between populations estimated as $F_{\mathrm{ST}}$ / (1- F $F_{\mathrm{ST}}$ ) (Rousset \& Raymond 1997). In order to test the regression models, all the pairwise probabilities were transformed with the natural logarithm to account for the wide variability and the skewness towards zero values. Correlation was tested using the shortest marine distance, distance along the shore, habitat continuity ( $\mathrm{km}$ of rocky shore $/ \mathrm{km}$ of shore), average probability obtained from the LNS model and the index of directionality as predictors.

The slope of linear regression between genetic differentiation and logarithm of geographic distance was used to derive the distance at which a limit of $F_{\mathrm{ST}}=0.2$ was reached. We assessed the potential of multiple regressions models from a combination of predictors to improve the data fitting when these met assumptions for multiple regression. Akaike information criteria (AIC) and Bayesian information criterion (BIC) were adopted to assess the model efficiency in predicting the data in the model selection phase. We generated a confidence set of models to help formal inference using model likelihood and Akaike weight (Johnson \& Omland 2004).

\section{Results}

No significant linkage between loci was detected after Bonferroni correction. Most loci showed high polymorphism, ranging from 12 (Ct2.10 and Ct4.4.) to 36 (Ct4.2) total alleles, with the exception of locus $\mathrm{Ct} 2.3$ with only three alleles. No multilocus genotype clones were found.

Significant deviation from HWE was observed at most of the loci and populations (Table 1). Null alleles were detected at three loci (Ct2.10, Ct4.2 and Ct4.3), but these were not consistent across populations. Even after repeated extractions, some populations showed lower amplification rates at these loci (especially Capo Gallo and Altavilla), possibly inflating null allele detection. Global $F_{\mathrm{ST}}$ estimated with the ENA method for null allele correction (0.292) showed little difference from uncorrected $F_{\mathrm{ST}}$ (0.308). The highest allelic richness, standardized by sampling to the maximum common population size $(\mathrm{N}=25)$, was observed in Capo Gallo (4.76) and the lowest in the eastern populations of Otranto and Torre Uluzzo with 2.75 and 2.29, respectively (Table 1).

\section{Genetic differentiation}

Genetic divergence was significant between all populations $(P=0.001)$, including at $100-\mathrm{m}$ distances $(P=0.012)$. The smallest but significant $F_{\mathrm{ST}}$ value was found between Capo Gallo sites A and B $\left(F_{\mathrm{ST}}=0.017\right)$ while the highest genetic distance was detected between Mazara and Torre Uluzzo populations, the westernmost and one of the easternmost populations, respectively, with an $F_{\mathrm{ST}}$ of 0.510 (Fig. S2, Supporting information).

Only few individuals could be attributed to another population based on their genotype as first-generation migrants based on an assignment test with a frequencybased method (Paetkau et al. 1995) implemented by GENECLASs2 (Piry et al. 2004) (Fig. S3, Supporting information). These were mainly between sites A, B and C inside Capo Gallo population, with an evident predominant direction from the exposed side (A) towards the inside of the bay (C).

Cluster analysis showed that the optimal number of clusters identified by lower BIC is 10, which

Table 1 Summary population genetics statistics for each sampling site

\begin{tabular}{lccccc}
\hline Population & $N$ & $H_{\mathrm{E}}$ & $H_{\mathrm{O}}$ & Allelic richness & $F_{\mathrm{IS}}$ \\
\hline CAPO GALLO A & 30 & 0.60 & 0.53 & 4.29 & 0.121 \\
CAPO GALLO B & 30 & 0.65 & 0.53 & 4.76 & $0.190^{*}$ \\
CAPO GALLO C & 30 & 0.56 & 0.50 & 4.51 & $0.109^{*}$ \\
CROTONE & 31 & 0.54 & 0.37 & 3.92 & $0.317^{*}$ \\
OTRANTO & 31 & 0.36 & 0.28 & 2.75 & $0.230^{*}$ \\
ALTAVILLA & 33 & 0.52 & 0.37 & 2.97 & $0.296^{*}$ \\
PORTO PALO & 34 & 0.62 & 0.53 & 4.26 & $0.148^{*}$ \\
MAZARA & 29 & 0.47 & 0.36 & 3.42 & $0.219^{*}$ \\
SANT'ELIA & 35 & 0.55 & 0.48 & 3.8 & $0.134^{*}$ \\
TORRE ULUZZO & 25 & 0.26 & 0.26 & 2.29 & 0.011 \\
\hline
\end{tabular}

$N$, number of sampled individuals; $H_{\mathrm{e}}$, expected heterozygosity; Ho, observed heterozygosity; Allelic richness after 999 bootstrapping; $F_{\mathrm{IS}}$, inbreeding coefficient.

*Significant probability for $F_{\mathrm{IS}}>0$. 
corresponds to the actual number of populations (including Capo Gallo as subpopulations). The strongest decrease in BIC was found at the first three clusters. Two of them correspond, as expected, to the cluster of populations around Palermo and the cluster of eastern populations (Otranto and Torre Uluzzo), as locations inside these clusters were geographically closer. However, the third cluster included the populations of southern Sicily and the mainland population of Crotone, which are hundreds of kilometres apart and separated by the Strait of Sicily (Fig. S4, Supporting information). Yet, these locations were predicted to be connected by oceanographic currents, and particle dispersal simulation confirmed this observation (Fig. 2).

The analysis of molecular variance attributed $64 \%$ of the genetic variance to the intrapopulation level. The remaining $36 \%$ was attributed to interpopulations variance: $20 \%$ was assigned to the distance among clusters and $16 \%$ among populations. F-statistic among clusters resulted to be similar to the F-statistics among population within clusters (0.201 and 0.195 , respectively).

\section{Fine-scale autocorrelation}

We discarded one of the molecular markers (Ct2.10) for this analysis because the locus showed a low rate of amplification in some transects. Spatial autocorrelation analysis across sites showed an overall decline in $\mathrm{r}$ with distance. At small spatial scales (within the 10 metres distance), significant positive $r$ values were observed in the first metre distance and an x-intercept at about 3.3 metres (Fig. 3a). Patterns of decline in $r$ values were consistent across transects A, B and C, and we found no significant differences associated to distance classes (T2 and omega heterogeneity tests: $P<0.01$ ). Higher scale analysis, considering pairwise distances between elements of transects, showed that kinship decreased faster within the smaller classes up to $10 \mathrm{~m}$ while slowly decreasing and oscillating inside the null hypothesis CI for higher distances, and declining again reaching significantly negative values at about $200 \mathrm{~m}$ (Fig. 3). We replicated the spatial autocorrelation analysis in Sant'Elia, where the coordinates of each of the 35 specimens were recorded. The maximum distance among sample pairs was only $34 \mathrm{~m}$; however, similar patterns of decrease in kinship coefficients could be found (Fig. S5, Supporting information).

\section{Modelling}

A total of 125 favourable habitat patches were found based on satellite image of rocky shores. After gridding, this resulted in a habitat continuity index expressed as rate of rocky shore by coastline distance, varying from 0.38 (discontinuous patches, separated by unsuitable habitats) to 1 for the contiguous suitable rocky coastlines. The lowest values were recorded between the eastern populations of Crotone and Torre Uluzzo, as most of the coast of the Gulf of Taranto and the Calabria Ionian shore is sandy and unsuitable for the species.

The LNS using HYCOM data tracked the geographic position of 134640 particles released from 1496 cells with favourable habitats (1 481040 particles for the 11year period) (Fig. 2). Most connectivity events occurred in the first days of simulation, as the average time of effective connectivity events was ca. 2 days (1.97 day \pm 1.77 ). Despite the maximum allowed pelagic duration of 30 days used in this study, the longer connectivity event was accomplished in only 17.83 days. This period of ca. 18 days is well within the time when fucoid reproductive material is viable while unattached (at least for 24 days, Monteiro et al. 2016). After this maximal connectivity event observed, particles were pushed offshore or transported to regions outside the scope of our study.

The resulting trajectories yielded two asymmetric matrices: a direct connectivity matrix averaged for the 11-year period and a stepping-stone matrix. Direct connectivity resulted in few valid pairwise probabilities, as most of the populations were not oceanographically connected by our simulated floating rafts. In contrast, stepping-stone probabilities were always resolved in at least one direction between paired sites. Probabilities ranged widely, from maximum values (averaged between sites) of 0.997 for the very close populations of Sant'Elia and Altavilla to a minimum of 5.46E-15 between Altavilla and Torre Uluzzo.

All the predictors tested were significant, but there were important differences in the ability to explain the data (Table 2). Linearized $F_{\mathrm{ST}}$ levels were highly correlated to geographical distance, both expressed as shortest marine distance (Adjusted $R^{2}=0.59$ ) and as coastline distance (Adjusted $R^{2}=0.68$ ). Including only the 12 site pairs which presented direct connectivity, without taking into account the stepping-stone option, still leads to a positive correlation between genetic distance and coastal distance $\left(R^{2}=0.55, P<0.01\right)$ as well as between genetic distance and the combination of coastal distance and average direct probability $\left(R^{2}=0.70, P<0.01\right)$. The single-term model of coastline distance was not significantly different (delta $\mathrm{AIC}=0.99$ ) from the stepping-stone model of average probability of connectivity. Both were highly correlated to estimated genetic distance (Adjusted $R^{2}=0.68$ and 0.67 , respectively), and both performed better than the shortest marine distance to explain 


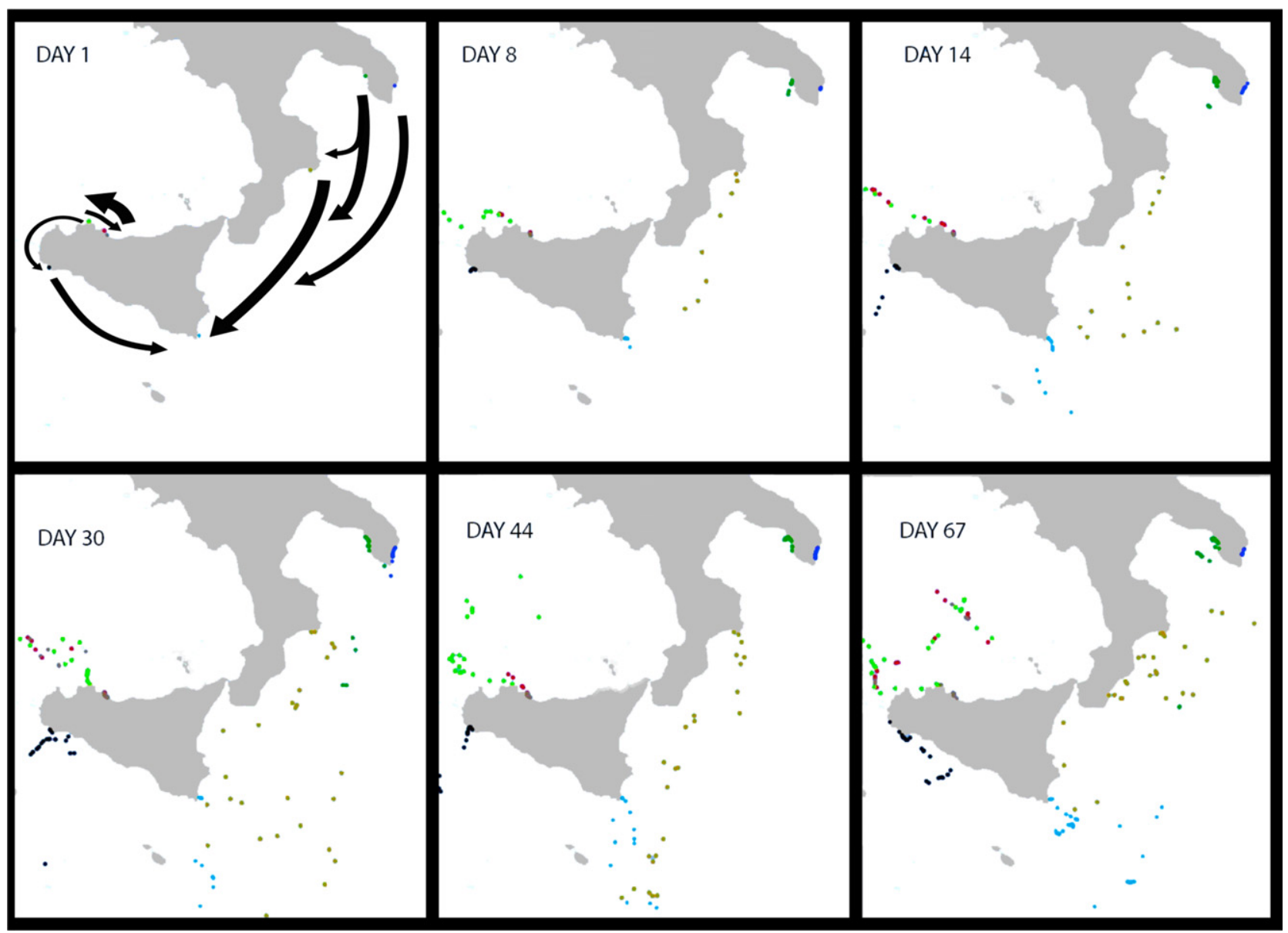

Fig. 2 Example snapshots of particle dispersal simulations. Shown after 1, 8, 14, 30, 44 and 67 days of simulation of particles originating from eight populations over one season. Each colour represents a particle released from one sampling site floating for 30 days and advected by oceanic velocity fields derived from HYCOM. Arrows at day 1 are proportional to the estimated probabilities of direct connectivity among populations based on the particle simulation.

our data (model likelihood $L_{\text {marine }}=0.02$ ). However, the model based on average probability from stepping-stone oceanographic transport did not appear to produce a better fit than a combination of habitat continuity and coastal distance. These two variables explained $73 \%$ of the variation in genetic differentiation and were a better predictor model according to Akaike criteria, but the difference to the steppingstone model was not significant according to model likelihood (AIC $=-21.57$; of $L_{\text {two-term }}=0.88$ ) and was just as good as best single-term models with a more conservative diagnostic (BIC $=-14.40$ and -14.33 , respectively).

The directionality index was not a very good predictor of genetic differentiation $\left(R^{2}=0.27 ; P\right.$ (F test) $=0.0015$ ), but significantly increased the fitting of the observations when added to other models. Our best-fit model (Fig. 4) was obtained adding the information of directionality to the two-term model $\left(R^{2}=0.78\right.$;
AIC $=-28.80)$, significantly interacting with coastline distance $\left(P_{(t \text { test })}<0.05\right)$ and rocky shore percentage $(P$ $(\mathrm{t}$ test) $=0.001)$.

\section{Discussion}

Populations of Cystoseira amentacea were strongly differentiated and connected by very low migration rates, leading to significant genetic distance even at small spatial scales. The capacity to predict genetic differentiation was improved when dispersal probability across available rocky habitat was estimated by simulating stepping-stone directional transport mediated by ocean currents.

\section{Genetic differentiation between populations}

Populations of $C$. amentacea had strong differentiation at all geographical scales, from a few metres to hundreds 

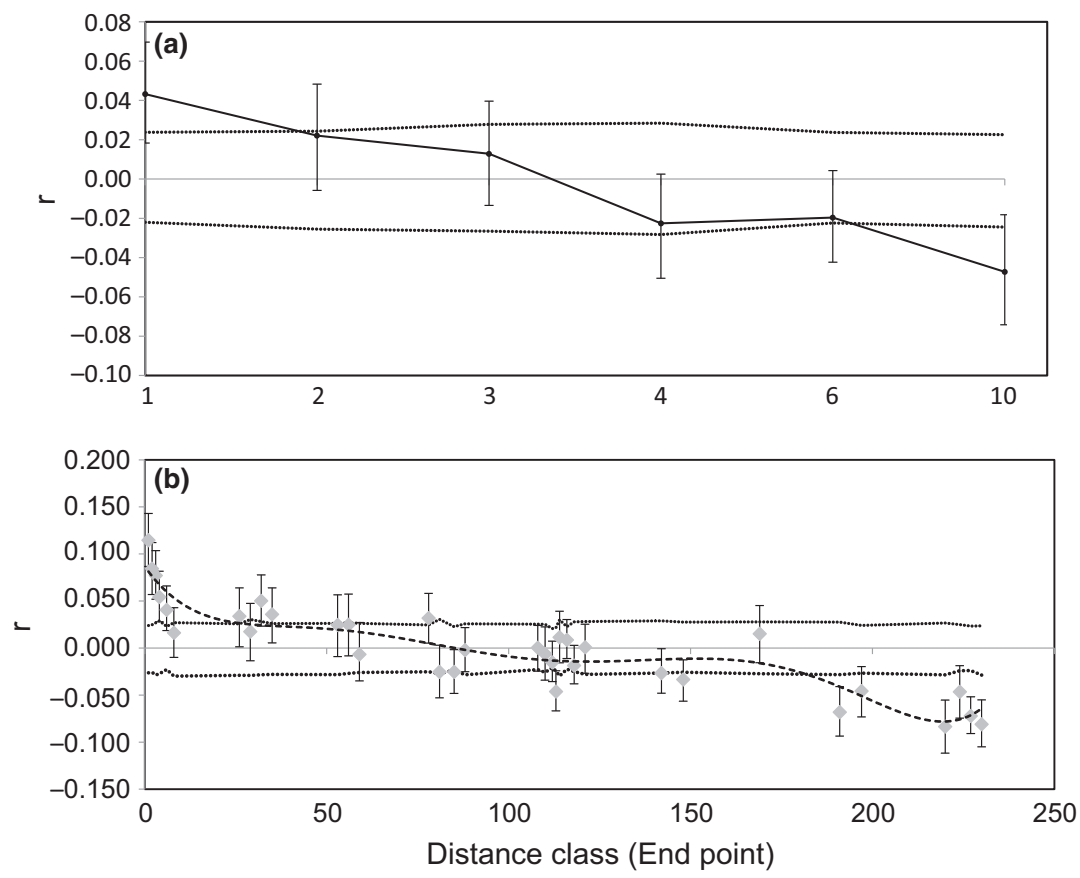

Fig. 3 Correlograms showing mean kinship coefficient (diamonds) as a function of geographical distance classes within transect (combined correlogram of the three transects) (a) and across all transects along the whole area (b) at Capo Gallo. Classes were chosen to keep similar number of observations/class. Dotted lines represent $95 \%$ confidence interval around the null hypothesis of relatedness by chance. In (b) the dotted line shows a fitted sixth-order polynomial line.

Table 2 Summary of model testing

\begin{tabular}{|c|c|c|c|c|}
\hline Predictor variable & $\begin{array}{l}\text { Adjusted } r^{2} / \text { Adjusted } r^{2} \\
\text { after ENA correction }\end{array}$ & $P$ values & $\mathrm{AIC} / \mathrm{BIC}$ & Model likelihood \\
\hline Coastline distance & $0.68 / 0.60$ & $* * *$ & $-18.63 /-14.33$ & 0.017 \\
\hline Marine distance & $0.59 / 0.54$ & $* * *$ & $-11.22 /-6.92$ & 0.0004 \\
\hline Habitat continuity & $0.57 / 0.54$ & $* * *$ & $-9.57 /-5.27$ & 0.0002 \\
\hline Directionality index & $0.27 / 0.24$ & $* *$ & $6.98 / 11.28$ & $4.616 \mathrm{e}-08$ \\
\hline Average probability & $0.67 / 0.58$ & $* * *$ & $-17.65 /-13.35$ & 0.010 \\
\hline Coastline distance + habitat continuity & $0.73 / 0.67$ & $* *$ & $-21.57 /-14.40$ & 0.073 \\
\hline $\begin{array}{l}\text { Coastline distance }+ \text { habitat continuity } \\
+ \text { Directionality index }\end{array}$ & $0.78 / 0.73$ & $\begin{array}{l}\text { Coast:rock* } \\
* * * \\
\text { Coast:rock** } \\
\text { Coast:index* }\end{array}$ & $-26.80 /-16.76$ & $\mathrm{~W}_{\text {best }}=0.91$ \\
\hline
\end{tabular}

The adjusted coefficients of determination $\left(r^{2}\right)$ before and after ENA correction for null alleles are reported. Significance of regression is also indicated $(*=0.05 ; * *=0.01 ; * * *=0.001)$. AIC and BIC $=$ Akaike and Bayesian model selection criteria Model likelihood (L) and Akaike weight (Wbest) are also shown (following Johnson \& Omland 2004).

of kilometres. Genetic differentiation was comparable to populations of other brown algae (Durrant et al. 2014), such as the fucoids Fucus vesiculosus (Tatarenkov et al. 2007; Assis et al. 2014), Pelvetia canaliculata (Neiva et al. 2014) or Bifurcaria bifurcata (Neiva et al. 2015). Similar differentiation had been estimated for the same species using random amplified polymorphic DNA (RAPD) markers at similar spatial scales (Susini et al. 2007a). As expected from intertidal algae with such a low-dispersal life history, the sampled populations were almost completely genetically isolated.

Geographically closer populations were not always the most connected. The sites along the southernmost coastlines of the mainland (Crotone) and Sicily island (Porto Palo and Mazara) were more connected than expected, while sites south and north of Sicily were highly differentiated from each other. This supports the hypothesis that the Ionian Stream in the Sicily channel represents a dispersal barrier between these populations, limiting rafting drift around the Sicily Island. This hydrographic feature and the difference in water density between the water masses of the Western and Eastern Mediterranean across the Sicily Strait had been already reported as a main driver of genetic differentiation in various species (Zardoya et al. 2004; Debes et al. 2008; Serra et al. 2010; Villamor et al. 2014), 


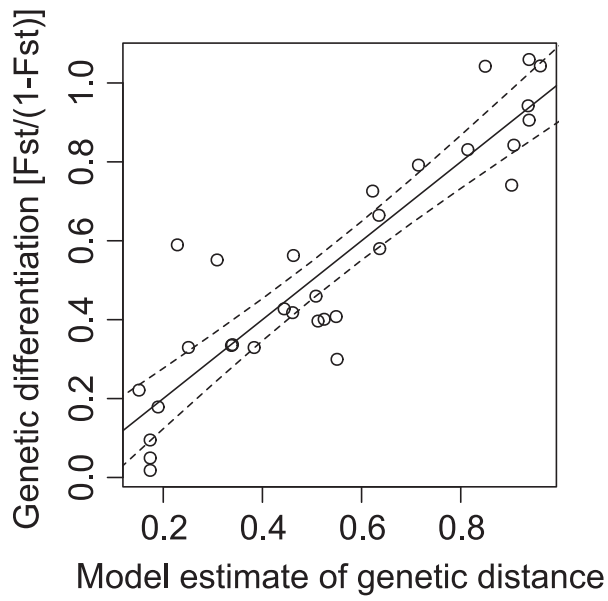

Fig. 4 Best-fit regression model (using coastal distance, habitat continuity and directionality index) to predict genetic differentiation among eight Cystoseira amentacea populations in southern Italy (see Table 2).

which could contribute to maintain the divergence established by past vicariant events (Arnaud-Haond et al. 2007).

The eastern populations of mainland southern Italy, Otranto and Torre Uluzzo were very isolated. LNS simulation showed that the marine currents in this area tend to push onshore the drifting particles and allow only occasional rafts to move offshore towards other suitable sites.

\section{Genetic structure within populations}

The genetic variance attributed to intrapopulation differences was high and consistent with a previous study using RAPD markers (Susini et al. 2007a). Our spatial autocorrelation analyses showed that individuals start to diverge within distances of a few metres, and significant genetic differences can be found among sites only $100 \mathrm{~m}$ apart along a continuous rocky fringe. This is consistent with the observation that recruitment of C. amentacea from settling embryos occurs predominantly within $20-40 \mathrm{~cm}$ from a natural population (Mangialajo et al. 2012), while large-distance dispersal may only take place by rafting (Thibaut et al. 2014), and with the high intrapopulation genetic variance here found. We hypothesize that the observed kinship similarity pattern may be explained by different dispersal processes acting on the species at different geographical scales. On one side, fucoid algae release their gametes under calm water conditions (Pearson \& Serrão 2006) that minimize gamete dilution, suggesting that mating occurs by selfing or between neighbouring individuals that are expected to be more related on average. Our results support this hypothesis because nearly all populations had significant heterozygote deficits. Plus the negatively buoyant propagules tend to fall close to the parent algae, leading to clustering of related individuals and strong correlation of kinship with distance. On the other side, in the genus Cystoseira, the female gametes remain attached to the parental algae even after fertilization and germination, for a few days (e.g. Engelen et al. 2008); therefore, the water motion conditions may change between the timing of gamete release/mating and the timing of settlement a few days later. As C. amentacea is most common along exposed coastlines, it is conceivable that occasionally, such propagules can be transported further apart and mixed in the water column. Furthermore, when water movement increases enough, dislocated fertile algae, although not buoyant, could be transported hundreds of metres away or even further if associated to other floating rafts (Thiel \& Gutow 2005), in agreement with the observed colonization of artificial structures at over $3 \mathrm{~km}$ from natural populations (Thibaut et al. 2014). The latter process would act along the whole geographical scale while the former would cover distances up to a few tens of metres. Our autocorrelation analysis could only be partially replicated, and caution should be taken before generalizing the results to other geographical areas with different oceanographic conditions. Replicating this analysis across sites would allow to understand whether similar general processes and patterns can be found, and support that is to be linked to the reproductive life history of the species.

\section{Stepping-stone directional oceanographic transport}

Gene flow was strongly related to marine currents even though connectivity between sites was often only possible by means of stepping-stone dispersal because direct oceanographic transport was never achieved. The oceanographic transport model revealed that, where direct connectivity of particles was possible, transport by currents explained the observed genetic differentiation better than coastal distance alone even in species with propagules that sink and attach immediately below the parents. Furthermore, the inclusion of a directionality index based on the stepping-stone simulation produced the best-fit model explaining genetic differentiation of our populations. This provides strong support for a key role of rafting in population connectivity of low-dispersive marine taxa, allowing them to be strongly influenced by oceanographic transport as observed in species with planktonic life stages that persist in the water column for long (e.g. Klein et al. 2016) or short (e.g. Alberto et al. 2011) periods.

Population genetic structure results from past historical events and present reproductive and migratory 
patterns. Our results suggest that at the multiple spatial scales analysed in this study, the present population pattern is determined and maintained by present low gamete dispersal within population and by raft-drifting between populations rather than colonization history. Although all populations were highly differentiated, rare successful migration events might be sufficient to preserve the natural levels of connectivity, as reported for giant kelp based on present oceanographic patterns simulated over 11 years (Alberto et al. 2011).

Stepping-stone dispersal explained observed connectivity better than habitat continuity. However, habitat continuity can well describe observed genetic differentiation over an extended spatial scale, comprising discontinuities (Alberto et al. 2011), even better when combined with other predictors. The addition of a directionality index predictor is an innovative approach that produced the best-fit model, accounting for the evident asymmetry in current flow, and therefore indicating a coupled asymmetric genetic flow among populations.

\section{Future directions and implications}

Our results showed a dependency of dispersal on ocean currents, supporting the raft association hypothesis, but some genetic patterns still remain unexplained by the simulation. The drifting of reproductively mature algae has been suggested as one of the main mechanisms for dispersal over long distances, for species sharing similar life-history traits and reproductive strategies as C. amentacea (Coleman \& Brawley 2005). However, C. amentacea lacks flotation vesicles, and rafts tend to sink rapidly. Our simulation model was based on the hypothesis that reproductive fragments can float for longer distances when associated to other species rafting with floating vesicles, namely Sargassum spp. and Cystoseira compressa (Esper) Gerloff \& Nizamuddin, often closely coexisting in the same areas (direct observation). However, rafts might not be able to cover the distance between populations separated by long continuous sandy shores (e.g. between Otranto and Crotone) where observed levels of genetic differentiation were explained by a combination of habitat discontinuity and geographic distance. This is an aspect where more work is clearly needed. Experimental approaches to test raft duration and viability in different associations could help clarifying the issue and possibly increase model accuracy. Even more important, the model was based on inferred habitat presence, but mapping of the actual distribution of C. amentacea would be essential for better extrapolation as well as a priority for conservation.

Our results have important implication for two of the main conservation and management strategies suggested for canopy-forming algae: the use of marine protected areas (MPAs) and restoration practices. The establishment of MPAs potentially favours the recovery of macroalgae forests by increasing predation pressure on grazers (Babcock et al. 2010) or by eliminating sources of anthropogenic disturbance (Thibaut et al. 2016). Networks of MPAs should also allow maintaining connectivity among fragmented populations and increase resilience to future environmental changes (Frankham et al. 2002; Coleman et al. 2011). However, little is known about the real connectivity of Mediterranean MPAs (Marti-Puig et al. 2013). Urbanization and other anthropic pressures on the seaside are locally depleting many populations of canopy-forming seaweeds (Benedetti-Cecchi et al. 2001; Mangialajo et al. 2008; Perkol-Finkel \& Airoldi 2010; Strain et al. 2014; Thibaut et al. 2015), while currently offering limited possibilities for expansion (Ferrario et al. 2016). Lack of connectivity among MPAs and habitat degradation along the coast may decrease the genetic variability and hamper the resilience and adaptation of these endangered habitat-forming species, possibly limiting the expected ecological and socio-economic benefits of protection. Restoration of Cystoseira forests on both natural and artificial substrata is an alternative management strategy to counteract the local decline of these species (Falace et al. 2006; Susini et al. 2007b; Perkol-Finkel et al. 2012; Gianni et al. 2013). However, precaution should be taken when designing restoration interventions for C. amentacea as the connectivity between populations on short temporal scales can only be guaranteed at very small distances. The loss of the species from large, fragmented areas would be hardly reversible even by restoration, as limited dispersal would not allow recolonization in short time scales. This implies that restoration can still be effective to foster recovery if some natural populations are present in the area, and if adequate habitat patches can serve as stepping stones for migrants. This knowledge can help select priority areas for conservation and restoration, as well as incentive a better planning, design and management of marine urbanized areas to mitigate habitat degradation and provide potentially suitable stepping stones (e.g. greenblue infrastructure) for threatened native populations (Perkol-Finkel et al. 2012).

In conclusion, this study is pioneer in combining local-scale genetic analysis and oceanographic modelling to understand mechanisms of dispersal and to give insight into species life-history traits for Mediterranean canopies of brown algae. Explicit modelling of stepping-stone dynamics and inclusion of habitat continuity allowed explaining most of the genetic variability in the region, suggesting that integrating the life-history processes and directional information can help to 
better describe and predict population patterns and evolution. This is crucial to understand the potential for adaptation and restoration under scenarios of increasing anthropogenic and climatic stressors and habitat modifications.

\section{Acknowledgements}

RB was funded through a MARES Grant (Doctoral Programme in Marine Ecosystem Health and Conservation, EU- 512002-12010-1-BE-EMJD). MARES is a Joint Doctorate programme selected under Erasmus Mundus coordinated by Ghent University (FPA 2011-0016). Check www.mares-eu.org for extra information. This study was also supported by: FCT (Portugal) projects EXTANT, GENEKELP and MARFOR; postdoc fellowship ref. SFRH/BPD/63703/2009 and SFRH/BPD/107878/2015 to AHE; postdoctoral fellowship to JA SFRH/BPD/111003/ 2015; and project TETRIS (Observing, modelling and Testing synergies and TRade-offs for the adaptive management of multiple Impacts in coastal Systems, PRIN 2011, Italian Ministry of Education, University and Research). We thank three anonymous reviewers who provided helpful suggestion to improve this manuscript, Marta Valente (CCMAR) for the genotyping work and Dr. Francesco Paolo Mancuso (UNIBO) for the priceless help in the sampling campaign.

\section{References}

Airoldi L, Beck MW (2007) Loss, status and trends for coastal marine habitats of europe. Oceanography and Marine Biology: An Annual Review, 45, 345-405.

Airoldi L, Ballesteros E, Buonomo R et al. (2014) Marine forests at risk: solutions to halt the loss and promote the recovery of Mediterranean canopy-forming seaweeds. Proceedings of the 5 th Mediterranean Symposium on Marine vegetation. Portoroz, Slovenia. 2014.

Airoldi L, Turon X, Perkol-Finkel S, Rius M (2015) Corridors for aliens but not for natives: effects of marine urban sprawl at a regional scale. Diversity and Distributions, 21, 755-768.

Alberto F (2013) MsatAllele: Visualizes the scoring and binning of microsatellite fragment sizes. $\mathrm{R}$ package version 1.05 . http: / /CRAN.R-project.org / package=MsatAllele

Alberto F, Raimondi P, Reed D (2010) Habitat continuity and geographic distance predict population genetic differentiation in giant kelp. Ecology, 91, 49-56.

Alberto F, Raimondi PT, Reed DC et al. (2011) Isolation by oceanographic distance explains genetic structure for Macrocystis pyrifera in the Santa Barbara Channel. Molecular Ecology, 20, 2543-2554.

Arnaud-Haond S, Migliaccio M, Diaz-Almela E et al. (2007) Vicariance patterns in the Mediterranean Sea: east-west cleavage and low dispersal in the endemic seagrass Posidonia oceanica. Journal of Biogeography, 34, 963-976.

Assis J, Serrão EA, Claro B, Perrin C, Pearson GA (2014) Climate-driven range shifts explain the distribution of extant gene pools and predict future loss of unique lineages in a marine brown alga. Molecular Ecology, 23, 2797-2810.

Assis J, Zupan M, Nicastro KR, Zardi GI, McQuaid CD, Serrão EA (2015) Oceanographic conditions limit the spread of a marine invader along southern Africa shores. PLoS ONE, 10, e0128124.

Babcock RC, Shears NT, Alcala AC et al. (2010) Decadal trends in marine reserves reveal differential rates of change in direct and indirect effects. Proceedings of the National Academy of Sciences of the United States of America, 107, 18256-18261.

Ballesteros E, Torras X, Pinedo S et al. (2007) A new methodology based on littoral community cartography dominated by macroalgae for the implementation of the European Water Framework Directive. Marine Pollution Bulletin, 55, 172-180.

Belkhir K, Borsa P, Chikhi L, Raufaste N, Bonhomme F (19962004) GENETIX 4.05, Logiciel Sous Windows TM Pour la Génétique des Populations. Laboratoire Génome, Populations, Interactions, CNRS UMR 5000, Université de Montpellier II, Montpellier, France.

Benedetti-Cecchi L, Pannacciulli F, Bulleri F et al. (2001) Predicting the consequences of anthropogenic disturbance: large-scale effects of loss of canopy algae on rocky shores. Marine Ecology Progress Series, 214, 137-150.

Chapuis M-P, Estoup A (2007) Microsatellite null alleles and estimation of population differentiation. Molecular Biology and Evolution, 24, 621-631.

Chassignet EP, Hurlburt HE, Smedstad OM et al. (2007) The HYCOM (HYbrid Coordinate Ocean Model) data assimilative system. Journal of Marine Systems, 65, 60-83.

Chevin L-M, Lande R, Mace GM (2010) Adaptation, plasticity, and extinction in a changing environment: towards a predictive theory. PLoS Biology, 8, e1000357.

Coleman MA, Brawley SH (2005) Are life history characteristics good predictors of genetic diversity and structure? A case study of the intertidal alga Fucus spiralis (heterokontophyta; phaeophyceae). Journal of Phycology, 41, 753-762.

Coleman MA, Chambers J, Knott NA et al. (2011) Connectivity within and among a network of temperate marine reserves. PLoS ONE, 6, e20168.

Collins CJ, Fraser CI, Ashcroft A, Waters JM (2010) Asymmetric dispersal of southern bull-kelp (Durvillaea antarctica) adults in coastal New Zealand: testing an oceanographic hypothesis. Molecular Ecology, 19, 4572-4580.

Coscia I, Robins P, Porter J (2012) Modelled larval dispersal and measured gene flow: seascape genetics of the common cockle Cerastoderma edule in the southern Irish Sea. Conservation Genetics, 14, 451-466.

Crandall ED, Treml EA, Barber PH (2012) Coalescent and biophysical models of stepping-stone gene flow in neritid snails. Molecular Ecology, 21, 5579-5598.

Debes PV, Zachos FE, Hanel R (2008) Mitochondrial phylogeography of the European sprat (Sprattus sprattus L., Clupeidae) reveals isolated climatically vulnerable populations in the Mediterranean Sea and range expansion in the northeast Atlantic. Molecular Ecology, 17, 3873-3888.

Durrant HMS, Burridge CP, Kelaher BP et al. (2014) Implications of macroalgal isolation by distance for networks of marine protected areas. Conservation Biology: the Journal of the Society for Conservation Biology, 28, 438-445.

Engelen A, Espirito-Santo C, Simões T et al. (2008) Periodicity of propagule expulsion and settlement in the competing native and invasive brown seaweeds, Cystoseira humilis and Sargassum muticum (Phaeophyta). European Journal of Phycology, 43, 275-282. 
Engelen AH, Costa J, Bermejo R, Marba N, Duarte CM, Serrão EA (2016) A population genetics toolbox for the threatened canopy-forming brown seaweeds Cystoseira tamariscifolia and C. amentacea (Fucales, Sargassaceae). Journal of Applied Phycology, 1-3 in press. doi: 10.1007/s10811-016-0964-7.

Excoffier L, Smouse P, Quattro J (1992) Analysis of molecular variance inferred from metric distances among DNA haplotypes: application to human mitochondrial DNA restriction data. Genetics, 131, 479-491.

Falace A, Zanelli E, Bressan G (2006) Algal transplantation as a potential tool for artificial reef management and environmental mitigation. Bulletin of Marine Science, 78, 161-166.

Falace A, Alongi G, Cormaci M et al. (2010) Changes in the benthic algae along the Adriatic Sea in the last three decades. Chemistry and Ecology, 26, 77-90.

Ferrario F, Iveša L, Jaklin A et al. (2016) The overlooked role of biotic factors in controlling the ecological performance of artificial marine habitats. Journal of Applied Ecology, 53, 16-24.

Floyd RW (1962) Algorithm 97: Shortest path. Communications of the ACM, 5, 344-348.

Frankham R, Briscoe DA, Ballou JD (2002) Introduction to Conservation Genetics. Cambridge University Press, Cambridge.

Fraser CI, Thiel M, Spencer HG, Waters JM (2010) Contemporary habitat discontinuity and historic glacial ice drive genetic divergence in Chilean kelp. BMC Evolutionary Biology, 10, 203.

Galindo HM, Olson DB, Palumbi SR (2006) Seascape genetics: a coupled oceanographic-genetic model predicts population structure of Caribbean corals. Current Biology: CB, 16, 1622 1626.

Gianni F, Bartolini F, Airoldi L et al. (2013) Conservation and restoration of marine forests in the Mediterranean Sea and the potential role of Marine Protected Areas. Advances in Oceanography and Limnology, 4, 83-101.

Hoarau G, Coyer JA, Stam WT, Olsen JL (2007) A fast and inexpensive DNA extraction/purification protocol for brown macroalgae. Molecular Ecology Notes, 7, 191-193.

ISPRA (2015) Annuario dei Dati Ambientali. Istituto Superiore per la Protezione e la Ricerca Ambientale - Settore Editoria, Roma.

Iveša L, Djakovac T, Devescovi M (2016) Long-term fluctuations in Cystoseira populations along the west Istrian Coast (Croatia) related to eutrophication patterns in the northern Adriatic Sea. Marine Pollution Bulletin, 106, 162-173.

Johansson ML, Banks MA, Glunt KD, Hassel-Finnegan HM, Buonaccorsi VP (2008) Influence of habitat discontinuity, geographical distance, and oceanography on fine-scale population genetic structure of copper rockfish (Sebastes caurinus). Molecular Ecology, 17, 3051-3061.

Johnson JB, Omland KS (2004) Model selection in ecology and evolution. Trends in Ecology \& Evolution, 19, 101-108.

Jombart T (2008) adegenet: a R package for the multivariate analysis of genetic markers. Bioinformatics (Oxford, England), 24, 1403-1405.

Jombart T, Devillard S, Balloux F (2010) Discriminant analysis of principal components: a new method for the analysis of genetically structured populations. BMC Genetics, 11, 94 .

Jones P (2007) Point-of-View: Arguments for conventional fisheries management and against no-take marine protected areas: only half of the story? Reviews in Fish Biology and Fisheries, 17, 31-43.
Kawecki TJ, Ebert D (2004) Conceptual issues in local adaptation. Ecology Letters, 7, 1225-1241.

Kawecki T, Holt R (2002) Evolutionary consequences of asymmetric dispersal rates. The American Naturalist, 160, 333-347.

Klein M, Teixeira S, Assis J, Serrão EA, Gonçalves EJ, Borges R (2016) High interannual variability in connectivity and genetic pool of a temperate clingfish, matches oceanographic transport predictions. PLOS ONE, 11, e0165881.

Lett C, Verley P, Mullon C et al. (2008) A Lagrangian tool for modelling ichthyoplankton dynamics. Environmental Modelling \& Software, 23, 1210-1214.

Mangialajo L, Chiantore M, Cattaneo-Vietti R (2008) Loss of fucoid algae along a gradient of urbanisation, and structure of benthic assemblages. Marine Ecology Progress Series, 358, 63-74.

Mangialajo L, Chiantore M, Susini M-L et al. (2012) Zonation patterns and interspecific relationships of fucoids in microtidal environments. Journal of Experimental Marine Biology and Ecology, 412, 72-80.

Mannino AM, Mancuso FP (2009) Guida all'identificazione delle Cistoseire (Area Marina Protetta "Capo Gallo-Isola delle Femmine"). Progetto AMPOCYS. Tipografia Alba, Palermo.

Marti-Puig P, Costantini F, Rugiu L, Ponti M, Abbiati M (2013) Patterns of genetic connectivity in invertebrates of temperate MPA networks. Advances in Oceanography and Limnology, 4, 138-149.

McKay JK, Christian CE, Harrison S, Rice KJ (2005) “How Local Is Local?"-a review of practical and conceptual issues in the genetics of restoration. Restoration Ecology, 13, 432-440.

Monteiro CA, Paulino C, Jacinto R, Serrão EA, Pearson GA (2016) Temporal windows of reproductive opportunity reinforce species barriers in a marine broadcast spawning assemblage. Scientific Reports, 6, 29198.

Neiva J, Pearson GA, Valero M, Serrão EA (2012) Fine-scale genetic breaks driven by historical range dynamics and ongoing density-barrier effects in the estuarine seaweed Fucus ceranoides L. BMC Evolutionary Biology, 12, 78.

Neiva J, Assis J, Fernandes F, Pearson GA, Serrão EA (2014) Species distribution models and mitochondrial DNA phylogeography suggest an extensive biogeographical shift in the high-intertidal seaweed Pelvetia canaliculata. Journal of Biogeography, 41, 1137-1148.

Neiva J, Assis J, Coelho NV, Fernandes F, Pearson GA, Serrão EA (2015) Genes left behind: climate change threatens cryptic genetic diversity in the canopy-forming seaweed Bifurcaria bifurcata. PLoS ONE, 10, e0131530.

Norton TA (1976) Why is Sargassum muticum so invasive? British Phycological Journal, 11, 197-198.

Norton TA, Mathieson AC (1983) The biology of unattached seaweeds. Progress in Phycological Research, 2, 333-386.

Opdam P, Wascher D (2004) Climate change meets habitat fragmentation: linking landscape and biogeographical scale levels in research and conservation. Biological Conservation, 117, 285-297.

Paetkau D, Calvert W, Stirling I, Strobeck C (1995) Microsatellite analysis of population structure in Canadian polar bears. Molecular Ecology, 4, 347-354.

Peakall R, Smouse PE (2006) genalex 6: genetic analysis in Excel. Population genetic software for teaching and research. Molecular Ecology Notes, 6, 288-295. 
Pearson GA, Serrão EA (2006) Revisiting synchronous gamete release by fucoid algae in the intertidal zone: fertilization success and beyond? Integrative and Comparative Biology, 46, 587-597.

Perkol-Finkel S, Airoldi L (2010) Loss and recovery potential of marine habitats: an experimental study of factors maintaining resilience in subtidal algal forests at the Adriatic Sea. PLoS ONE, 5, e10791.

Perkol-Finkel S, Ferrario F, Nicotera V, Airoldi L (2012) Conservation challenges in urban seascapes: promoting the growth of threatened species on coastal infrastructures. Journal of Applied Ecology, 49, 1457-1466.

Piry S, Alapetite A, Cornuet J-M et al. (2004) GENECLASS2: a software for genetic assignment and first-generation migrant detection. The Journal of Heredity, 95, 536-539.

Quantum GIS Development Team (2014) Quantum GIS Geographic Information System. Open Source Geospatial Foundation Project. http://qgis.osgeo.org

R Core Team (2014) R: A Language and Environment for Statistical Computing. R Foundation for Statistical Computing, Vienna, Austria. URL http://www.R-project.org/.

Robvieux P (2013) Conservation des populations de Cystoseira en régions Provence-Alpes-Côte-d'Azur et Corse.

Robvieux P, Videment J, Ribout C et al. (2012) First characterization of eight polymorphic microsatellites for Cystoseira amentacea var. stricta (Fucales, Sargassaceae). Conservation Genetics Resources, 4, 923-925.

Rousset F (1997) Genetic differentiation and estimation of gene flow from F-statistics under isolation by distance. Genetics, 1228, 1219-1228.

Rousset F, Raymond M (1997) Statistical analyses of population genetic data: new tools, old concepts. Trends in Ecology $\mathcal{E}$ Evolution, 12, 313-317.

Schultz J, Feldheim K (2008) Global phylogeography and seascape genetics of the lemon sharks (genus Negaprion). Molecular Ecology, 17, 5336-5348.

Selkoe KA, Watson JR, White C et al. (2010) Taking the chaos out of genetic patchiness: seascape genetics reveals ecological and oceanographic drivers of genetic patterns in three temperate reef species. Molecular Ecology, 19, 37083726.

Serra IA, Innocenti AM, Di Maida G et al. (2010) Genetic structure in the Mediterranean seagrass Posidonia oceanica. Disentangling past vicariance events from contemporary patterns of gene flow. Molecular Ecology, 19, 557-568.

Siegel D, Kinlan B (2003) Lagrangian descriptions of marine larval dispersion. Marine Ecology Progress series, 260, 8396.

Smouse PE, Peakall R (1999) Spatial autocorrelation analysis of individual multiallele and multilocus genetic structure. Heredity, 82, 561-573.

Soltan D, Verlaque M, Boudouresque CF, Francour P (2001) Changes in macroalgal communities in the vicinity of a Mediterranean sewage outfall after the setting up of a treatment plant. Marine Pollution Bulletin, 42, 59-70.

Storfer A, Murphy MA, Evans JS et al. (2007) Putting the "landscape" in landscape genetics. Heredity, 98, 128-142.

Strain EMA, Thomson RJ, Micheli F, et al. (2014) Identifying the interacting roles of stressors in driving the global loss of canopy-forming to mat-forming algae in marine ecosystems. Global Change Biology, 20, 3300-3312.
Strain EMA, van Belzen J, van Dalen J, et al. (2015) Management of local stressors can improve the resilience of marine canopy algae to global stressors. PLOS ONE, 10, e0120837.

Sunday JM, Popovic I, Palen WJ, Foreman MGG, Hart MW (2014) Ocean circulation model predicts high genetic structure observed in a long-lived pelagic developer. Molecular Ecology, 23, 5036-5047.

Susini ML, Thibaut T, Meinesz A, Forcioli D (2007a) A preliminary study of genetic diversity in Cystoseira amentacea (C. Agardh) Bory var. stricta Montagne (Fucales, Phaeophyceae) using random amplified polymorphic DNA. Phycologia, 46, 605-611.

Susini ML, Mangialajo L, Thibaut T, Meinesz A (2007b) Development of a transplantation technique of Cystoseira amentacea var. stricta and Cystoseira compressa. Hydrobiologia 580, 241244.

Tatarenkov A, Jönsson RB, Kautsky L, Johannesson K (2007) genetic structure in populations of fucus vesiculosus (phaeophyceae) over spatial scales from $10 \mathrm{~m}$ to $800 \mathrm{~km}$. Journal of Phycology, 43, 675-685.

Thibaut T, Blanfuné A, Markovic L et al. (2014) Unexpected abundance and long-term relative stability of the brown alga Cystoseira amentacea, hitherto regarded as a threatened species, in the north-western Mediterranean Sea. Marine Pollution Bulletin, 89, 305-323.

Thibaut T, Blanfuné A, Boudouresque CF, Verlaque M (2015) Decline and local extinction of Fucales in the French Riviera: the harbinger of future extinctions? Mediterranean Marine Science, 16, 206-224.

Thibaut T, Blanfuné A, Boudouresque C-F et al. (2016) Unexpected temporal stability of cystoseira and sargassum forests in port-cros, one of the oldest mediterranean marine national parks. Cryptogamie, Algologie, 37, 61-90.

Thiel M, Gutow L (2005) The ecology of rafting in the marine environment. I. The floating substrata. Oceanography and Marine Biology: an Annual Review, 42, 181-264.

Thompson RC, Crowe TP, Hawkins SJ (2002) Rocky intertidal communities: past environmental changes, present status and predictions for the next 25 years. Environmental Conservation, 29, 168-191.

Thrush SF, Hewitt JE, Lohrer AM, Chiaroni LD (2013) When small changes matter: the role of cross-scale interactions between habitat and ecological connectivity in recovery. Ecological Applications, 23, 226-238.

Toonen R, Hughes S (2001) Increased throughput for fragment analysis on an ABI Prism ${ }^{\circledR} 377$ automated sequencer using a membrane comb and STRand software. BioTechniques, 31, 1320-1325.

Treml E A, Halpin PN, Urban DL, Pratson LF (2007) Modeling population connectivity by ocean currents, a graph-theoretic approach for marine conservation. Landscape Ecology, 23, 1936

Van Oosterhout C, Hutchinson WF, Wills DPM, Shipley P (2004) Micro-checker: software for identifying and correcting genotyping errors in microsatellite data. Molecular Ecology Notes, 4, 535-538.

Villamor A, Costantini F, Abbiati M (2014) Genetic structuring across marine biogeographic boundaries in rocky Shore Invertebrates (M Hart, Ed,). PLoS ONE, 9, e101135.

Weir B, Cockerham C (1984) Estimating F-statistics for the analysis of population structure. Evolution, 38, 1358-1370. 
White C, Selkoe KA, Watson J et al. (2010) Ocean currents help explain population genetic structure. Proceedings Biological Sciences / The Royal Society, 277, 1685-1694.

Xu X, Chassignet EP, Price JF, Özgökmen TM, Peters H (2007) A regional modeling study of the entraining Mediterranean outflow. Journal of Geophysical Research: Oceans, 112, 21562202.

Young CM, He R, Emlet RB et al. (2012) Dispersal of deep-sea larvae from the intra-American seas: simulations of trajectories using ocean models. Integrative and Comparative Biology, 52, 483-496.

Zardoya R, Castilho R, Grande C et al. (2004) Differential population structuring of two closely related fish species, the mackerel (Scomber scombrus) and the chub mackerel (Scomber japonicus), in the Mediterranean Sea. Molecular Ecology, 13, 1785-1798.

Zavodnik N, Ivesa L, Travizi A (2002) Note on recolonisation by fucoid algae Cystoseira spp. and Fucus virsoides in the North Adriatic Sea. Acta Adriatica, 43, 25-32.

R.B. designed the research, performed the research, analysed the data and wrote the manuscript. J.A. designed the research, particle dispersal model, data analysis and wrote part of the manuscript. F.F. performed laboratory analysis and manuscript revision. A.E. designed the research, performed manuscript revision and helped in logistic assistance. L.A. designed the research and manuscript revision. E.A.S. designed the research and wrote part of the manuscript.

\section{Data accessibility}

Microsatellite scorings, information on populations' sites and all the data used in the analysis can be found in the Dryad repository with entry doi:10.5061/dryad.dk563.

\section{Supporting information}

Additional supporting information may be found in the online version of this article.

Fig. S1 Historical records of $C$. amentacea from the literature.

Fig. S2 Triangular matrix of genetic differentiation.

Fig. S3 Number of first generation migrant for each population pairs estimated according to Paetkau at al. (1995) criterion in Geneclass2 software .

Fig. S4 Plot of discriminant Analysis of Principal Components (DAPC) approach implemented in the adegenet $R$ package (Jombart 2008)

Fig. S5 Autocorrelation analysis with samples from Sant'Elia population.

Fig. S6 Linear regression between genetic differentiation and logarithm of geographic distance. 